Corrigendum

\title{
Corrigendum to "Nursery Growing Media: Agronomic and Environmental Quality Assessment of Sewage Sludge-Based Compost"
}

\author{
Barbara De Lucia, ${ }^{1}$ Giuseppe Cristiano, ${ }^{1}$ Lorenzo Vecchietti, ${ }^{1}$ Elvira Rea, ${ }^{2}$ and \\ Giovanni Russo' \\ ${ }^{1}$ Department of Agro-Environmental and Territorial Sciences (DISAAT), University of Bari Aldo Moro, Via G. Amendola 165/A, \\ 70125 Bari, Italy \\ ${ }^{2}$ CRA, Agricultural Research Council, Research Centre for the Soil-Plant System, Via Della Navicella 2-4, 00184 Rome, Italy
}

Correspondence should be addressed to Barbara De Lucia; barbara.delucia@uniba.it

Received 2 November 2017; Accepted 16 November 2017; Published 31 December 2017

Copyright (C) 2017 Barbara De Lucia et al. This is an open access article distributed under the Creative Commons Attribution License, which permits unrestricted use, distribution, and reproduction in any medium, provided the original work is properly cited.

In the article titled "Nursery Growing Media: Agronomic and Environmental Quality Assessment of Sewage Sludge-Based Compost" [1], there is a close similarity with the authors' published article: Vecchietti, L., De Lucia, B., Russo, G., Rea, E., and Leone, A. (2013). Environmental and Agronomic Evaluation of Containerized Substrates Developed from Sewage Sludge Compost for Ornamental Plant Production. Acta Hortic. 1013, 431-439. doi: 10.17660/ActaHortic.2013.1013.54 [2], which was not cited or discussed, since it was not published yet.

The AESS article [1] builds on a preliminary work presented as a conference communication and published on the corresponding conference proceedings [2]. This publication was in preparation before the AESS article [1], although it was finally published later in November 2013. The Acta Hortic. conference paper [2] reports preliminary results obtained in the period from August 2007 to June 2008, while the AESS article [1] reports the results of a new research carried out in the period from December 2012 to May 2013; Introduction has considerably wider coverage; the section of Materials and Methods contains the physicochemical and analytical aspects of sewage sludge and compost, and it also reports measurements and analytical methods very extensively. Results and Discussion is considerably longer and more articulated and contains 23 bibliographic references and two tables with the concentrations of macro- and micronutrients in plant tissues. Reference list contains 42 bibliographic references.
There are some similarities between Tables 3-8 in [2] and Tables 2-7 in [1], respectively. This occurred since an initial bulk quantity of substrates was created by mixing the different starting raw materials (2007). The same substrates were used in the two trials. Chemical compositional analyses were carried out only at the beginning after mixture preparation (2008) and were not repeated before the two trials, considering that no variation is expected in the chemical composition of a mixture in a short-medium term period. Other substrate properties that could have been affected by the time were measured before each trial, and so, this explains the changes or the similarities observed in the physicochemical properties of the substrates used.

Figure 2 in the AESS article [1] is the same as Figure 1 in the Acta Hortic. conference paper [2]. The LCA of the production process of both compost and substrates was considered in the Acta conference paper; it focuses mainly on topics related to environmental analysis. The AESS article [1] only shows the results of the LCA of substrates according to their composition. In the two publications, the assumptions of substrate composition and supply distances are the same. The results are presented as percentages in order to better understand the differences between a substrate and the other. With this type of display, the differences due to the compost are not perceptible. Since the $\mathrm{C} / \mathrm{N}$ ratio for compost production must be constant, small variations in composted organic matrices do not substantially alter the environmental analysis of substrates. 
Figures 1(a) and 1(c) in the AESS article [1] are highly similar to Figures 2 and 4 in the Acta Hortic. conference paper [2]. Although the two trials were conducted in different years and locations, given that the treatments were the same (substrates that, as said above, came from a single original batch), Bougainvillea's response was quite similar.

\section{Acknowledgments}

The authors want to remember the author Elvira Rea who collected some of the data and performed some of the analyses and who sadly died in September 2015.

\section{Supplementary Materials}

The raw data of both articles. (Supplementary Materials)

\section{References}

[1] B. De Lucia, G. Cristiano, L. Vecchietti, E. Rea, and G. Russo, "Nursery growing media: agronomic and environmental quality assessment of sewage sludge-based compost," Applied and Environmental Soil Science, vol. 2013, Article ID 565139, 10 pages, 2013.

[2] L. Vecchietti, B. De Lucia, G. Russo, E. Rea, and A. Leone, "Environmental and agronomic evaluation of containerized substrates developed from sewage sludge compost for ornamental plant production," Acta Horticulturae, vol. 1, no. 1013, pp. 431-439, 2013. 

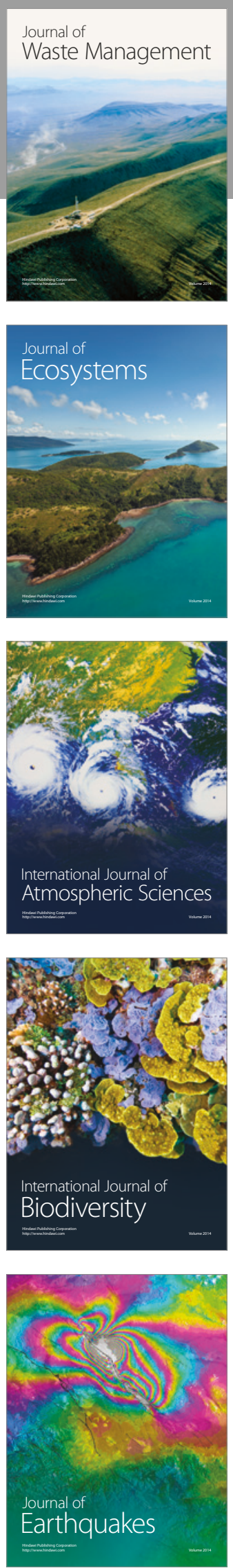
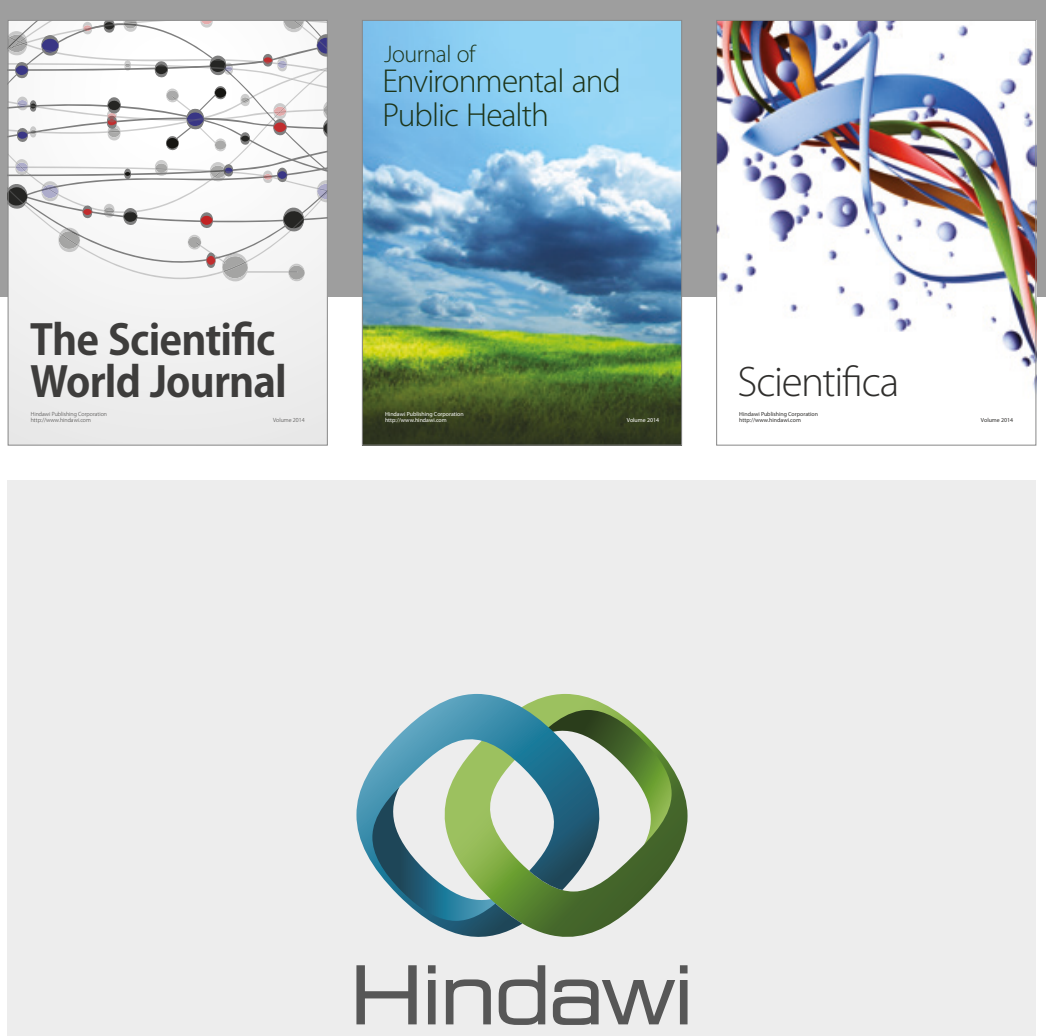

Submit your manuscripts at

https://www.hindawi.com
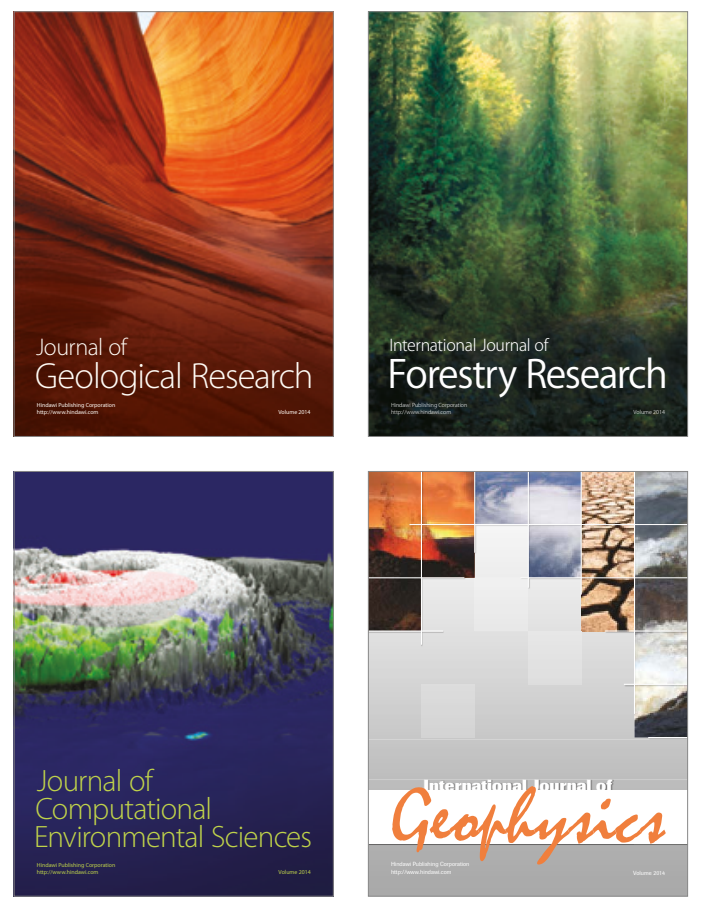
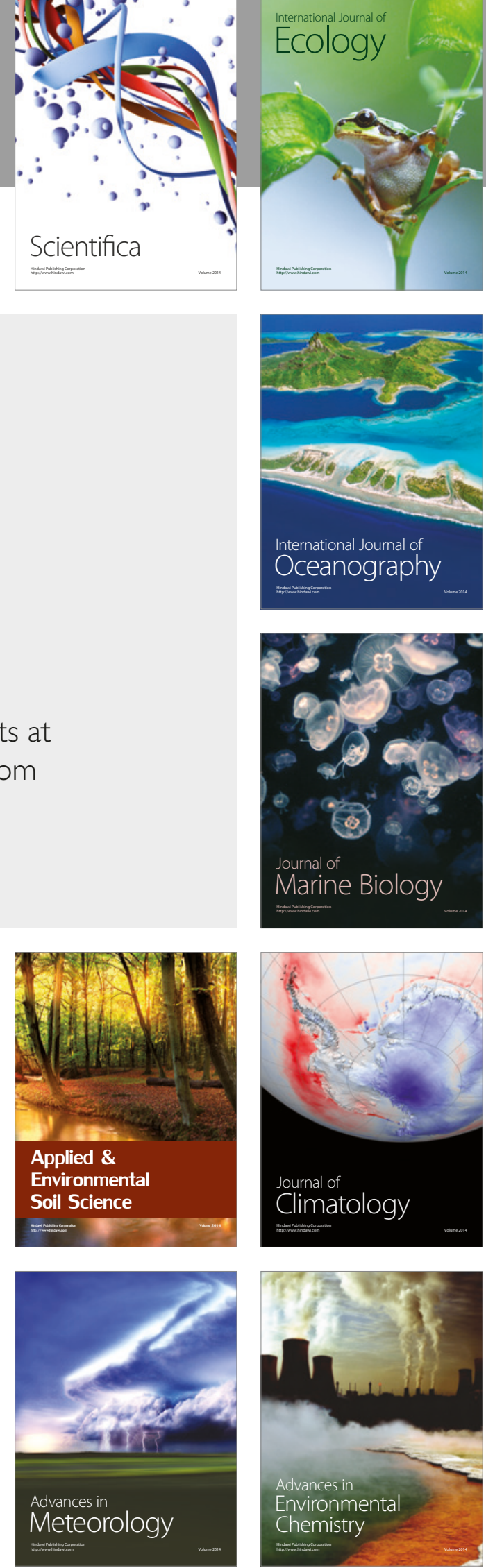